\section{MS15 P01}

Study of Bifurcated Hydrogen Bonding in Co-crystals with Chloranilic acid M. Adam, A. Parkin, \& C.C. Wilson, Dept. of Chemistry \& WestCHEM Research School, University of Glasgow.

E-mail: maadam@chem.gla.ac.uk

Keywords: Hydrogen-bonded molecular adducts, Visualization techniques, X-ray crystallography of samll molecules

X-ray single crystal diffraction is commonly used in structural chemistry. Unfortunately when used conventionally the data obtained lacks the sensitivity to determine accurate hydrogen atom parameters, which is of particular importance in hydrogen-bonded systems. By application of a multi-temperature approach, difference Fourier maps and programs like CrystalExplorer it is possible to gain insight into the temperature-dependent behavior of the hydrogen atoms and their interactions. Indication of the presence of proton disorder and migration can be observed $[1,2]$, determining the best candidate molecules for further study. These are then subjected, where possible, to neutron diffraction analysis to define fully the hydrogen atom behaviour [2]. A structural study of a series of co-crystals with chloranilic acid will be presented. The effects of temperature and $\mathrm{pKa}$ on the bifurcated hydrogen bonds will be discussed and the structures compared using Fourier difference maps, Hirshfeld surfaces and fingerprint plots [3].

[1] C C Wilson \& A E Goeta (2004). Angew Chem Int Ed Engl, 43, 2095-2099; C L Nygren, C C Wilson \& J F C Turner (2005). J Phys Chem A, 109, 2586-2593

[2] A Parkin, S M Harte, A E Goeta \& C C Wilson (2004). New J Chem, 28, 718-721

[3] M.A. Spackman and J.J. McKinnon (2002) CrystEngComm, $4,378-392$

\section{MS15 P02}

Cocrystals of 1,2-Bis(chloromercurio)

Tetrafluorobenzene with Netural Bidentate Lewis Bases. Mikhail Yu. Antipin a,b, Andrey A. Yakovenko ${ }^{\mathrm{a}}$, Jose H. Gallegos ${ }^{\mathrm{a}}$, Tatiana V. Timofeeva ${ }^{\mathrm{a}} \cdot{ }^{a}$ Department of Natural Sciences, New Mexico Highlands University, Las Vegas, NM 87701, USA; ${ }^{b}$ Institute of Organoelement Compounds, Russia Acedemy of Sciences, Moscow, 119991, Russia

E-mail:m_antipin@yahoo.com

In search for extraction agents for Lewis basis we studied cocrystallizastion of Lewis acids and basis. It was found before that the bidentate Lewis acid, 1,2bis(chloromercurio) tetrafluorobenzene $p-\left(\mathrm{C}_{6} \mathrm{~F}_{4}\right)(\mathrm{HgCl})_{2}$ (1) forms complexes with monodentane Lewis bases such as dimetylsulfoxide (DMSO), dimethylformamide (DMF), acetone, dimethyl methylphosphonate (DMMP), benzaldehyde, acetonitrile, THF and propylene oxide. Goal of this project was to find crystallization conditions and structural chartacteristics for complexes of 1 with bidentate Lewis bases including complexes with pharmaceuticals. For example, complex with nitrobenzene (2) $\left\{\left[p-\left(\mathrm{C}_{6} \mathrm{~F}_{4}\right)(\mathrm{HgCl})_{2}\right]\left(\mathrm{PhNO}_{2}\right)\right\}_{\mathrm{n}} \quad$ (3) contains one molecule of a

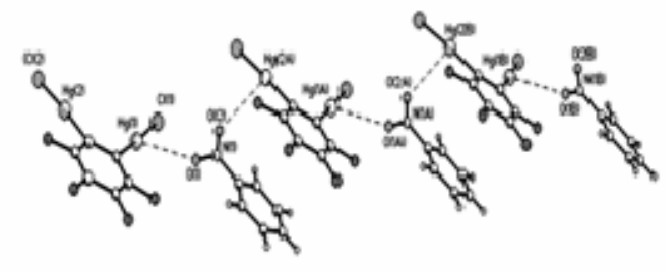

Lewis base per one molecule of $\mathbf{1}$. Complex $\mathbf{3}$ have chiral supramolecular structure (space group $\left(P 2_{1}\right)$, were each oxygen atom of nitro group of $\mathbf{2}$ is coordinated with one mercury atom of $\mathbf{1}$.

\section{MS15 P03 \\ Preparation and Reactivity of Nanosized Cocrystals Formed by Sonocrystallization Dejan-Krešimir Bučar ${ }^{\mathrm{a}}$, Leonard R. MacGillivray, ${ }^{\mathrm{a} D e p a r t m e n t}$ of Chemistry, University of Iowa, Iowa City, IA 52242, USA E-mail: dejan-kresimir-bucar@uiowa.edu}

Keywords: nanocrystalline materials, sonochemistry, photodimerization

Single crystals of macroscopic dimensions are not always appropriate for single-crystal-to-single-crystal (SCSC) reactions due to their mechanical properties (i.e. they crack). A recent study by Nakanishi [1] has described a method to achieve single-crystal-to-single-crystal (SCSC) reactivity within organic crystalline solids by reducing the crystal size to nanodimensions using a precipitation method. Having considered this study, we anticipated that a SCSC [2+2] photoreaction of supramolecular hydrogenbonded assemblies within co-crystals could be achieved by reducing the crystal size to nano- and submicron dimensions. In this contribution, we demonstrate the application of low-intensity ultrasonic radiation to cocrystals of composition 2(resorcinol) 2 (4,4'-bpe) $\mathbf{1}$ [where 4,4'-bpe = trans-1,2-bis(4-pyridyl)ethylene)] through sonocrystallization produces nano- and submicron-sized cocrystals that are shown to exhibit SCSC reactivity [2]. We also demonstrate that that the sonochemical treatment succeeds where sole precipitation fails. The SCSC reactivity of these assemblies was studied by proton nuclear magnetic resonance $\left({ }^{1} \mathrm{H}-\mathrm{NMR}\right)$ and $\mathrm{X}$ ray diffraction (XRPD) while the morphology of the crystalline samples was observed by scanning electron microscopy (SEM).
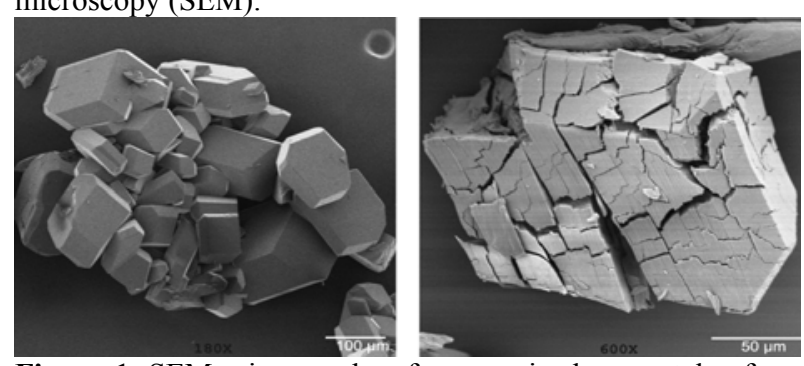

Figure 1. SEM micrographs of macro-sized cocrystals of 1 showing the effects of UV light: (a) before and (b) after photoreaction. 

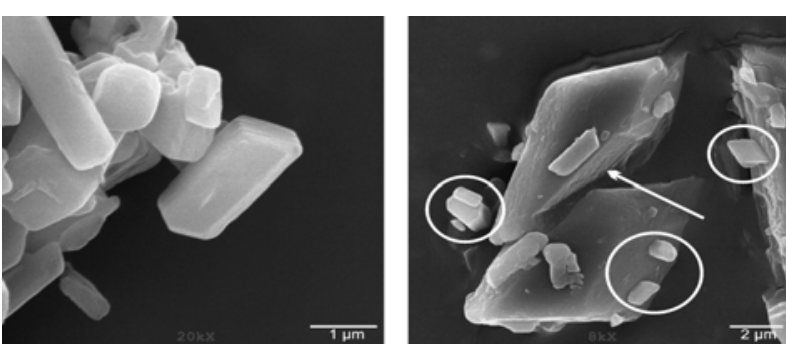

Figure 2. SEM micrographs of 1 grown via sonocrystallization: (a) before and (b) after photoreaction. Circles show intact crystals, while the arrow shows crack in a large crystal.

[1] Takahashi, S.; Miura, H.; Kasai, H.; Okada, S.; Oikawa, H.; Nakanishi, H. J. Am. Chem. Soc., 2002, 124, 10944.

[2] D.-K. Bučar, L. R. MacGillivray J. Am. Chem. Soc., 2007, 129,32 .

\section{MS15 P04}

Racemic resolution of $N$-protected DL-amino acids by crystallization of brucinium and strychninium diastereomeric salts. Agata Białońska, Zbigniew Ciunik Faculty of Chemistry, University of Wroclaw.Wroclaw, Poland. E-mail: bialonsk@eto.wchuwr.pl

Keywords: self-assembly supramolecular chemistry, recognition molecular, hydrogen bonding

Racemic resolution by fractional crystallization of diastereomeric salts remains one of the most useful methods in endeavor to obtain pure optically active compounds [1]. Therefore, it seems peculiar that only one pair of crystal structures of brucinium salts, as a result of racemic resolution, is known [2]. It seems to be a high selective for a given enantiomer, and reveals a low selectivity for various compounds (CSD, V. 5.27, 2006) [3]. For a given N-benzoyl-amino acid, there is known only one brucinium or strychninium diastereomeric salt. Pairs of crystals of brucinium or strychninium diastereomeric salts of $\mathrm{N}$-4-nitrobenzoyl-D- and of $\mathrm{N}-4$ nitrobenzoyl-L-amino acids, as well as, solid solutions have been obtained. Similarly, pairs of the diastereomeric salts of $N$-3,5-dinitrobenzoyl-D- and $N$-3,5-dinitrobenzoylL-amino acids have crystallized. In some other cases, strychnine and brucine appear an ineffective resolving agents in racemic resolution of $\mathrm{N}$-3,5-dinitrobenzoyl-DLamino acids, and the crystals of the double salts have been obtained. Thus, the selectivity of strychnine and brucine for a given enantiomer decrease in series of racemic resolution of $\mathrm{N}$-benzoyl- $>\mathrm{N}$-4-nitrobenzoyl- $>\mathrm{N}$-3,5dinitrobenzoyl-DL-amino acids. As far as we can see, there are the first cases of solid solutions of brucinium salts, as well as, of double brucinium salts, for which structures were determined.

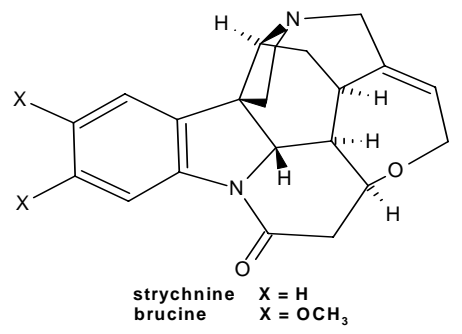

In most reported crystals containing brucine or strychnine moieties, among many only few donors participate in weak $\mathrm{C}-\mathrm{H} . . . \mathrm{O}$ and $\mathrm{C}-\mathrm{H} . . . \pi$ hydrogen bonds stabilizing common alkaloid self-assemblies. Depending on alkaloid self-assemblies, various active sites are formed at their surface. The active sites, by recognition of suitable part of anions or solvent molecules, provide appropriate surfaces for interactions in hydrophilic environment, from which the brucinium or strychninium salts were crystallized. Donor/acceptor capabilities of surfaces of alkaloid selfassemblies are related to donor/acceptor properties of resolved compound [4] or solvent [5]. Chiral discrimination depends on the nature of hydrogen bonds networks, involving resolving agent, solvent molecules and tertiary amine $\mathrm{N}$ atom.

[1] Jacques J., Collet A., Wilen S.H., Enantiomers, Racemates and Resolutions, Krieger Publishing Company, Malabar; Florida, 1991.

[2] Kuwata S., Tanaka J., Onda N., Yamada T., Miyazawa T., Sugiura M., In Y., Doi M., Inoue M., Ishida T., Bull. Chem. Soc. Jpn., 1993, 66, 1501.

[3] Allen F.H., Acta Cryst., 2002, B58, 380.

[4] Białońska A., Ciunik Z., Cryst. Eng. Comm., 2004, 6, 276,

[5] Białońska A., Ciunik Z., Acta Cryst., 2004, C60, o853.

\section{MS15 P05}

Crystal structures of the osteoporosis drug risedronate J. Brüning ${ }^{\mathrm{a}}$, E. Alig ${ }^{\mathrm{a}}$, B. Nachtsheim ${ }^{\mathrm{b}}$, M. Bolte ${ }^{\mathrm{a}}$, and

M. U. Schmidt ${ }^{\mathrm{a}}$ Institute of Inorganic and Analytical Chemistry, ${ }^{\mathrm{b}}$ Institute of Organic Chemistry and Chemical Biology, ${ }^{\mathrm{a}, \mathrm{b}}$ University of Frankfurt, Max-von-Laue-Str.7, 60438 Frankfurt am Main, Germany.

E-mail: bruening@chemie.uni-frankfurt.de

Keywords: risedronate, crystal structure, polymorphism

Risedronate (1) is a pyridinyl bisphosphonate inhibiting the osteoclast-mediated bone resorption. It is the most effective drug against osteoporosis up to now [1,2].

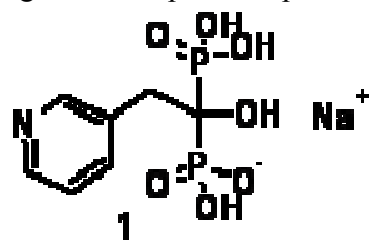

During a polymorph screening with over 100 experiments using different temperatures and solvents (e.g. dimethylsulf-oxide, N-methyl-pyrrolidone, alcohols, ethers and esters), we found 11 polymorphic and pseudopolymorphic forms, which we identified and characterised by X-ray powder diffraction and differential thermal analysis. 3 crystal structures of 1 were determined by single crystal X-ray diffraction.

[1] Diez-Perez A., Maturitas, 2002, 43, 19.

[2] Redman-Furey, N. et al., J. Pharm. Sci., 2005, 94, 893. 